\title{
Body mass index, type 2 diabetes, and left ventricular function
}

\author{
Katrine Dina Musaeus ${ }^{1}$ and Manan Pareek ${ }^{2,3^{*}}$ (1)
}

\begin{abstract}
A recent study found that among individuals with a preserved left ventricular ejection fraction $\geq 55 \%$, global longitudinal strain was significantly lower in overweight patients (i.e., body mass index $\geq 25 \mathrm{~kg} / \mathrm{m}^{2}$ ) with, but not in those without, type 2 diabetes mellitus. These results contrast previous observations of body mass index as a significant predictor of incident diastolic dysfunction and increased left ventricular mass index among subjects without prevalent diabetes. We discuss potential explanations for the observed discrepancies and general difficulties associated with cardiovascular risk assessment based on body mass index and related metabolic factors.
\end{abstract}

Keywords: Body mass index, Diabetes mellitus, type 2, Ventricular dysfunction, left, Ventricular function, left

\section{To the Editor}

We have read with great interest the study by Suto et al. on how overweight might affect left ventricular (LV) function in subjects with and without type 2 diabetes mellitus (T2DM) [1]. The authors evaluated 145 patients with T2DM and 90 healthy controls, matched on age, sex, and LV ejection fraction (LVEF). All participants had a preserved LVEF ( $\geq 55 \%$ ). The main finding was that global longitudinal strain (GLS) was significantly lower among overweight patients (i.e., body mass index $($ BMI $) \geq 25 \mathrm{~kg} / \mathrm{m}^{2}$ ) with T2DM, but not among those who were overweight without T2DM. It was suggested that the development of heart failure with preserved EF may be prevented by controlling overweight in patients with T2DM. We believe that this study warrants further discussion.

The results contrast previous observations of BMI as a significant predictor of incident diastolic dysfunction and increased LV mass index among subjects without diabetes at baseline [2]. Although GLS cannot be directly

\footnotetext{
*Correspondence: mananpareek@dadlnet.dk

${ }^{3}$ Cardiovascular and Metabolic Preventive Clinic, Department of Endocrinology, Centre for Individualized Medicine in Arterial Diseases (CIMA), Odense University Hospital, Sdr. Boulevard 29, 5000 Odense C, Denmark

Full list of author information is available at the end of the article
}

compared with traditional Doppler markers of diastolic function, one possible explanation for the discrepant findings may lie in the suboptimal utilization of BMI data in both studies. Indeed, given its J- or U-shaped association with clinical endpoints, BMI is too complex a variable to be used in a simple linear or dichotomized fashion [3-6]. Spline functions or fractional polynomial regression models may be preferable in such settings. As an aside, matching individuals on BMI might have enabled the investigators to tease out any independent effects of T2DM.

Numerically, it may seem as if the presence of overweight reduced GLS to a greater extent among patients with T2DM as compared with non-diabetics, and this is certainly supported by the Cardiovascular Continuum concept, by which hyperglycemia accelerates the cardiovascular aging process [7]. However, the potential for a type 2 error should not be overlooked. Assuming a 1:1 ratio of overweight versus non-overweight healthy controls, a sample size of 270 would have been sufficient to render a significant two-sided $\mathrm{P}$ value for the observed GLS difference of 0.6 , with $80 \%$ power. With the same power, 200 patients with T2DM would be required to show statistical significance at a difference of 1.0. This might explain why only a few echocardiographic variables reached statistically significant differences in 
Table 2 in the original paper [1]. Accordingly, we encourage the authors to provide the results of an appropriate interaction analysis to better clarify this issue.

Finally, in the previous study, BMI was independently associated with incident echocardiographic abnormalities at the expense of insulin sensitivity [2]. The frequent co-occurrence of insulin resistance, hyperinsulinemia, obesity, hypertension, and T2DM makes it difficult to dissect the separate role of each of these conditions for the development of subclinical cardiac damage, and studies of insulin and cardiac structure and function have revealed inconsistent findings [8-10]. Therefore, we believe the authors have a golden opportunity to examine associations between insulin and the most sensitive marker of impaired LV function, GLS.

\section{Abbreviations}

BMI: body mass index; EF: ejection fraction; GLS: global longitudinal strain; LV: left ventricle/left ventricular; LVEF: left ventricular ejection fraction; T2DM: type 2 diabetes mellitus.

\section{Authors' contributions}

Both authors (KM and MP) drafted the manuscript. Both authors read and approved the final manuscript.

\section{Authors' information}

Dr. Manan Pareek, MD, Ph.D., FESC is a cardiologist in training and has worked with cardiovascular epidemiology for more than 4 years. His Ph.D. thesis, entitled"The Interplay between Fasting Glucose, Echocardiography, and Biomarkers: Pathophysiological Considerations and Prognostic Implications" includes a large section on cardiac structural and functional implications of glycemic disturbances.

\section{Author details}

${ }^{1}$ Faculty of Health and Medical Sciences, University of Copenhagen, Blegdamsvej 3B, 2200 Copenhagen N, Denmark. ${ }^{2}$ Brigham and Women's Hospital Heart \& Vascular Center, Harvard Medical School, 75 Francis St, Boston, MA 02115, USA. ${ }^{3}$ Cardiovascular and Metabolic Preventive Clinic, Department of Endocrinology, Centre for Individualized Medicine in Arterial Diseases (CIMA), Odense University Hospital, Sdr. Boulevard 29, 5000 Odense C, Denmark.

\section{Acknowledgements}

None.

\section{Competing interests}

The authors declare that they have no competing interests.

Availability of data and materials

Not applicable.
Consent for publication

Not applicable.

Ethics approval and consent to participate

Not applicable.

Funding

None.

\section{Publisher's Note}

Springer Nature remains neutral with regard to jurisdictional claims in published maps and institutional affiliations.

Received: 11 December 2017 Accepted: 23 December 2017

Published online: 04 January 2018

\section{References}

1. Suto M, Tanaka H, Mochizuki Y, Mukai J, Takada H, Soga F, et al. Impact of overweight on left ventricular in type 2 diabetes mellitus. Cardiovasc Diabetol. 2017:16(1):145.

2. Nielsen ML, Pareek M, Gerke O, Leósdóttir M, Nilsson PM, Olsen MH. Greater body mass index is a better predictor of subclinical cardiac damage at long-term follow-up in men than is insulin sensitivity: a prospective, population-based cohort study. BMC Cardiovasc Disord. 2015;15:168.

3. Aune D, Sen A, Prasad M, Norat T, Janszky I, Tonstad S, et al. BMI and all cause mortality: systematic review and non-linear dose-response meta-analysis of 230 cohort studies with 3.74 million deaths among 30.3 million participants. BMJ. 2016;353:i2156.

4. Berrington de Gonzalez A, Hartge P, Cerhan JR, Flint AJ, Hannan L, MacInnis RJ, et al. Body-mass index and mortality among 1.46 million white adults. N Engl J Med. 2010;363(23):2211-9.

5. Zweng W, McLerran DF, Rolland B, Zhang X, Inoue M, Matsuo K, et al. Association between body-mass index and risk of death in more than 1 million Asians. N Engl J Med. 2011;364(8):719-29.

6. Tobias DK, Pan A, Jackson CL, O'Reilly EJ, Ding EL, Willett WC, et al. Bodymass index and mortality among adults with incident type 2 diabetes. N Engl J Med. 2014;370(3):233-44.

7. O'Rourke MF, Safar ME, Dzau V. The Cardiovascular Continuum extended: aging effects on the aorta and microvasculature. Vasc Med. 2010:15(6):461-8

8. Paolisso G, Galderisi M, Tagliamonte MR, de Divitis M, Galzerano D, Petrocelli A, et al. Myocardial wall thickness and left ventricular geometry in hypertensives: relationship with insulin. Am J Hypertens. 1997:10(11):1250-6.

9. Rutter MK, Parise H, Benjamin EJ, Levy D, Larson MG, Meigs JB. Impact of glucose intolerance and insulin resistance on cardiac structure and function: sex-related differences in the Framingham Heart Study. Circulation. 2003;107(3):448-54

10. Galvan AQ, Galetta F, Natali A, Muscelli E, Sironi AM, Cini G, et al. Insulin resistance and hyperinsulinemia: no independent relation to left ventricular mass in humans. Circulation. 2000;102(18):2233-8. 